Abstract-Penaeid shrimp fisheries, particularly those operating with bottom otter trawls, can generate high levels of bycatch. In 2014, a workgroup was formed to devise and test gear modifications in Pamlico Sound and the nearshore waters of North Carolina with the goal of improving bycatch reduction rates. Trials were conducted in 2015 and 2016 on large $(>12 \mathrm{~m})$, doublerigged industry vessels, and trials were conducted in 2017 on 1 double-rigged vessel and 3 smaller, twin-rigged vessels. A paired $t$-test and a randomization test were used to compare tows. The results of both tests indicate that 4 of the 14 gears tested achieved an average rate of finfish bycatch reduction that was $40 \%$ greater than that of the control gear. Shrimp loss in most gears tested was minimal. Three of the 4 gears that met the reduction goal for finfish bycatch employed a combination of increased codend mesh size and larger finfish escape openings relative to the control configuration. Relying on industry input and expert opinions as well as on past research to guide the selection of test gears and their design, the workshop members developed gear combinations that appear to meet the management objective for bycatch reduction. The results of this work provide direction for future testing in similar fisheries.

Manuscript submitted 2 April 2019. Manuscript accepted 4 December 2019. Fish. Bull. 117:372-385 (2019). Online publication date: 19 December 2019. doi: 10.7755/FB.117.4.9

The views and opinions expressed or implied in this article are those of the author (or authors) and do not necessarily reflect the position of the National Marine Fisheries Service, NOAA.

\title{
Simple gear modifications for achieving greater than $40 \%$ bycatch reduction in an estuarine shrimp trawl fishery
}

\author{
H. Kevin Brown (contact author) ${ }^{1}$ \\ Blake Price ${ }^{2}$ \\ Laura Lee ${ }^{3}$ \\ M. Scott Baker Jr. ${ }^{4}$ \\ Sara E. Mirabilio ${ }^{5}$
}

Email address for contact author: kevin.h.brown@ncdenr.gov

${ }^{1}$ Division of Marine Fisheries

North Carolina Department of Environmental Quality

3441 Arendell Street

Morehead City, North Carolina 28557

${ }^{2}$ Riverside Technology Inc. Beaufort Laboratory Southeast Fisheries Science Center National Marine Fisheries Service, NOAA 101 Pivers Island Road Beaufort, North Carolina 28516

\author{
${ }^{3}$ Division of Marine Fisheries \\ North Carolina Department of Environmental \\ Quality \\ 3441 Arendell Street \\ Morehead City, North Carolina 28557 \\ ${ }^{4}$ North Carolina Sea Grant Extension Program \\ University of North Carolina Wilmington Center \\ for Marine Science \\ 601 S. College Road \\ Wilmington, North Carolina, 28409 \\ ${ }^{5}$ North Carolina Sea Grant Extension Program \\ P.O. Box 699 \\ Manteo, North Carolina 27954
}

Bycatch in commercial fisheries remains an important and controversial topic in fisheries management and marine conservation both in the United States and around the world (Andrew and Pepperell, 1992; Crowder and Murawski, 1998; Hall et al., 2000; Kelleher, 2005; Davies et al., 2009; Portley et al. ${ }^{1}$ ). Warm-water penaeid shrimp fisheries, particularly those operating with bottom otter trawls, can generate high levels of bycatch (Andrew and Pepperell, 1992). Importantly, bycatch in the shrimp trawl fishery can have ecological, economic, and management repercussions (Hall et al., 2000).

\footnotetext{
${ }^{1}$ Portley, N., M. Westmeyer, and J. M. Garcia Caudilo. 2015. SFP report on the wild shrimp sector: bycatch in global shrimp fisheries, 15 p. Sustainable Fish. Partner. Found., Honolulu, HI. [Available from website.]
}

Efforts to reduce bycatch in shrimp trawl fisheries span decades (Watson and McVea, 1977; Vieira et al., 2017), and the conventional approach to addressing bycatch has been through gear modification to achieve bycatch reduction rather than elimination of trawl gear (Watson et al., 1999; Broadhurst, 2000; Eayrs, 2012). Gear modifications that are easy to deploy, are inexpensive, reduce bycatch, and maintain shrimp catch are more acceptable to the fishing industry than area or seasonal closures (Murray et al., 1992). Some of the earliest work focused on the development of the trawl efficiency device (TED), also known as the turtle excluder device, in efforts to exclude sea turtles from the gear (Watson and McVea, 1977). Subsequently, bycatch reduction devices (BRD) have been developed and tested in an attempt to exclude bycatch by size or behavior (Broadhurst, 2000). The use 
of TEDs and BRDs has been required by federal and state law since the early 1990s in all commercial shrimp trawl fisheries in the southeastern United States.

In the United States, penaeid shrimp account for approximately $11 \%$ of the $\$ 5.3$ billion total ex-vessel value reported for domestic fisheries in 2016 (NMFS ${ }^{2}$ ). Approximately $70 \%$ of domestic shrimp harvest occurs in the Gulf of Mexico, and North Carolina is typically the top producer among states on the East Coast. From 2013 through 2017, commercial fishermen in North Carolina landed an average of $4130 \mathrm{Mg}$ of shrimp with an ex-vessel value of $\$ 20.0$ million $\left(\mathrm{NCDMF}^{3}\right)$.

The fishery in North Carolina targets brown (Farfantepenaeus aztecus), pink (F. duorarum), and white (Litopenaeus setiferus) shrimp. All 3 species are considered annual crops, implying that natural mortality rather than fishing pressure has the greatest effect on population size (NCDMF, 2015). This fishery is unique among those in East Coast states and much of the Gulf of Mexico in that approximately 75\% of the shrimp harvest comes from inshore, estuarine waters (NCDMF, 2015). Approximately 92\% of the harvest is captured with bottom otter trawls because other gears, such as channel nets, skimmer trawls, and shrimp pots, are not generally suitable for operating in the deeper, often muddy estuarine systems (e.g., Pamlico Sound, North Carolina) (NCDMF, 2015).

The shrimp fishery in North Carolina is controversial because of the amount of finfish bycatch in the fishery and the resulting discard of commercially and recreationally valuable fish species, such as the southern flounder (Paralichthys lethostigma), summer flounder (P. dentatus), Gulf flounder (P. albigutta), weakfish (Cynoscion regalis), spot (Leiostomus xanthurus), and Atlantic croaker (Micropogonias undulatus) (Murray et al., 1992; SAFMC, 1996; NCDMF, 2015).

Management and research efforts to curb bycatch in North Carolina are longstanding and significant. In 1992, North Carolina became the first state on the East Coast to require BRDs in shrimp trawls (NCDMF, 2015). State fisheries biologists have tested existing BRDs (Holland ${ }^{4}$; McKenna and Monaghan ${ }^{5}$; Brown ${ }^{6}$ ), experimented with

\footnotetext{
${ }^{2}$ NMFS (National Marine Fisheries Service). 2017. Fisheries of the United States, 2016. NOAA Curr. Fish. Stat. 2016, 147 p. [Available from website.]

${ }^{3}$ NCDMF (North Carolina Division of Marine Fisheries). 2019. 2019 license statistics annual report, 424 p. Div. Mar. Fish., North Carolina Dep. Environ. Qual., Morehead City, NC. [Available from website.]

${ }^{4}$ Holland, B. F., Jr. 1989. Evaluation of certified trawl efficiency devices (TEDs) in North Carolina's nearshore ocean. North Carolina Dep. Nat. Resour. Comm. Dev., Div. Mar. Fish., Compl. Rep. Proj. 2-439-R, 38 p. [Available from website.]

${ }^{5}$ McKenna, S. A., and J. P. Monaghan Jr. 1993. Gear development to reduce bycatch in the North Carolina trawl fisheries. North Carolina Dep. Environ. Health Nat. Res., Div. Mar. Fish., Compl. Rep. Coop. Agreement No. NA90AA-H-SKO52, 59 p. [Available from website.]

${ }^{6}$ Brown, K. 2010. Interstate fisheries management program implementation for North Carolina. Study 2: documentation and reduction of bycatch in North Carolina fisheries. Job 1: compare catch rates of shrimp and bycatch of other species in standard (control) and modified (experimental) otter trawls in the Neuse River and Pamlico Sound, North Carolina. North Carolina Dep. Environ. Nat. Res., Div. Mar. Fish., Compl. Rep. NOAA Award No. NA08NMF474076, 23 p. [Available from website.]
}

modified trawls (He et al. ${ }^{7}$ ), and conducted statewide bycatch characterization studies $\left(\right.$ Brown $\left.^{8}\right)$. Academic scientists have partnered with industry to reduce bycatch on multiple occasions (Murray et al., 1992; Rulifson et al., 1992). Likewise, members of the commercial shrimp industry have participated in numerous collaborative research projects addressing bycatch issues, including at least 21 short-term projects funded by the North Carolina Sea Grant from 1995 through 2013 (information about these projects is available from website).

In 2014, the North Carolina shrimp fishery management plan was amended by the North Carolina Marine Fisheries Commission (NCMFC) to focus exclusively on reducing finfish bycatch in the bottom otter trawl fishery (NCDMF, 2015). The overall objective of the research reported here was to address this management goal by evaluating gear modifications capable of achieving bycatch reductions relative to control trawl gears while minimizing shrimp loss. To achieve this goal, the project team set forth the following objectives: 1) convene a workgroup to devise and prioritize experimental gears to be tested, 2) conduct comparable paired tows aboard commercial fishing vessels, and 3) compare results to catch data observed in control nets. The desired outcome was to develop technical solutions within 3 years that met a bycatch reduction target of $40 \%$ (above that achieved with a control gear), as recommended by the NCMFC, while maintaining shrimp catches.

\section{Materials and methods}

\section{Workgroup}

Prior to gear selection and testing, we convened a 12-member workgroup consisting of commercial fishermen, net makers, and industry representatives from North Carolina. Multiple international gear experts attended the first meeting and provided advice relevant to the needs of the fishery in North Carolina (Brown et al. ${ }^{9}$ ). The purpose of this workgroup was to provide feedback throughout the project, from gear

\footnotetext{
${ }^{7}$ He, P., C. Rillahan, K. Brown, T. Lewis. 2016. Design and test of a topless shrimp trawl to reduce finfish bycatch in Pamlico Sound, North Carolina, 55 p. Final report submitted to NOAA SaltonstallKennedy Grant Program for grant SMAST-CE-REP-2016-057. [Available from School Mar. Sci. Technol., Univ. Mass. Dartmouth, 285 Old Westport Rd., New Bedford, MA 02747-2300.]

${ }^{8}$ Brown, K. 2015. Characterization of the commercial shrimp otter trawl fishery in the estuarine and ocean (0-3 miles) waters of North Carolina, 165 p. Final report to the National Fish and Wildlife Foundation and the National Oceanic and Atmospheric Administration National Marine Fisheries Service for the study period August 2012-August 2015. Div. Mar. Fish., North Carolina Dep. Environ. Qual., Morehead City, NC. [Available from website.]

9 Brown, K., B. Price, L. Lee, S. Baker, and S. Mirabilio. 2017. Technical solutions to reduce bycatch in the North Carolina shrimp trawl fishery, 50 p. Final Report to the North Carolina Marine Fisheries Commission and the National Oceanic and Atmospheric Administration Bycatch Reduction Engineering Program for the study period June-July 2015 and July-September 2016. Div. Mar. Fish., North Carolina Dep. Environ. Qual., Morehead City, NC. [Available from website.]
} 


\section{Table 1}

Characteristics of the control and the 9 experimental shrimp otter trawls (gears) that were tested in Pamlico Sound and nearshore waters off North Carolina during 2015-2017. The state and federal fisheye bycatch reduction devices (BRDs), as constructed for this study, created openings of $131 \mathrm{~cm}^{2}$ and $258 \mathrm{~cm}^{2}$, respectively. All experimental gears included a typical net body, a trawl efficiency device (TED), one or more BRDs, and a codend. Some of the gears had TEDs with reduced bar spacing. The cost for an industry manufacturer to construct a single control gear for this study was $\$ 3000$. N/A=not applicable.

\begin{tabular}{|c|c|c|c|c|c|}
\hline \multirow[b]{2}{*}{ Year } & \multirow[b]{2}{*}{ Gear description } & \multicolumn{4}{|c|}{ Configuration } \\
\hline & & $\begin{array}{l}\text { TED bar } \\
\text { spacing } \\
(\mathrm{cm})\end{array}$ & BRD & $\begin{array}{l}\text { Codend } \\
\text { mesh size } \\
(\mathrm{cm})\end{array}$ & $\begin{array}{l}\text { Costs to } \\
\text { retrofit one } \\
\text { control net }\end{array}$ \\
\hline All & Control & 10.16 & 1 state fisheye & 3.81 & N/A \\
\hline \multirow[t]{5}{*}{2015} & Composite panel & 10.16 & $\begin{array}{l}\text { Composite panel, spooker cone, } \\
1 \text { state fisheye }\end{array}$ & 3.81 & $\$ 400$ \\
\hline & Reduced-bar TED & 7.62 & 1 state fisheye & 3.81 & $\$ 700$ \\
\hline & $\begin{array}{l}\text { Reduced-bar TED + square mesh panel + } \\
\text { 4.76-cm codend }\end{array}$ & 7.62 & $\begin{array}{l}1 \text { state fisheye, square mesh } \\
\text { panel }\end{array}$ & 4.76 & $\$ 1250$ \\
\hline & Ricky BRD & 10.16 & Ricky & 3.81 & $\$ 110$ \\
\hline & Double federal fisheyes $+4.76-\mathrm{cm}$ codend & 10.16 & 2 federal fisheyes & 4.76 & $\$ 600$ \\
\hline \multirow[t]{4}{*}{2016} & Virgil Potter BRD & 10.16 & 1 state fisheye, Virgil Potter & 3.81 & $\$ 275$ \\
\hline & Double federal fisheyes $+4.45-\mathrm{cm}$ codend & 10.16 & 2 federal fisheyes & 4.45 & $\$ 600$ \\
\hline & $\begin{array}{l}\text { Reduced-bar TED + double federal fisheyes + } \\
\text { 4.45-cm codend }\end{array}$ & 7.62 & 2 federal fisheyes & 4.45 & $\$ 1250$ \\
\hline & Virgil Potter BRD + 4.45-cm codend & 10.16 & 1 state fisheye, Virgil Potter & 4.45 & $\$ 800$ \\
\hline \multirow[t]{5}{*}{2017} & Reduced-bar TED & 7.62 & 1 state fisheye & 3.81 & $\$ 700$ \\
\hline & Reduced-bar TED + 4.13-cm codend & 7.62 & 1 state fisheye & 4.13 & $\$ 1225$ \\
\hline & $\begin{array}{l}\text { Reduced-bar TED + double state fisheyes + } \\
4.13-\mathrm{cm} \text { codend (summer) }\end{array}$ & 7.62 & 2 state fisheyes & 4.13 & $\$ 1250$ \\
\hline & $\begin{array}{l}\text { Reduced-bar TED + double state fisheyes + } \\
4.13-\mathrm{cm} \text { codend (autumn) }\end{array}$ & 7.62 & 2 state fisheyes & 4.13 & $\$ 1250$ \\
\hline & $\begin{array}{l}\text { Reduced-bar TED + double federal fisheyes + } \\
\text { 4.13-cm codend }\end{array}$ & 7.62 & 2 federal fisheyes & 4.13 & $\$ 1250$ \\
\hline
\end{tabular}

selection and testing to overall evaluation of the gear results and of an acceptable amount of shrimp loss. Meetings were held at the beginning of the project and following annual testing trials.

Selection of BRDs and gear combinations for testing in this study was guided by multiple factors, including existing state regulations, advice from international gear experts, and feedback from workgroup members and industry representatives. Additionally, a state management regulation issued by proclamation in 2015 after the start of this study mandated that shrimp fishermen install an additional $\mathrm{BRD}$, for a total of 2 devices, allowing various BRD combinations $\left(\mathrm{NCDMF}^{10}\right)$. The workgroup selected 14 gears by consensus for testing in 2015, 2016, and 2017 (Table 1).

\section{Gear testing procedures}

A formal procedure for comparing tows (experimental versus control) was developed and closely followed the

\footnotetext{
${ }^{10}$ NCDMF (North Carolina Division of Marine Fisheries). 2015. Re: Shrimp trawl BRD requirements. Proclamation SH-2-2015. Div. Mar. Fish., North Carolina Dep. Environ. Nat. Resour., Morehead City, NC. [Available from website.]
}

procedure outlined in the NOAA BRD testing manual $\left(\mathrm{NMFS}^{11}\right)$. A target of 60 successful paired tows was set for sampling in 2015, as mandated by the NCMFC, and a minimum target of 30 successful paired tows was set for the fishing seasons in 2016 and 2017 (NMFS $^{11}$ ). A successful tow was defined as the control and experimental trawl fishing without indication of occurrence of problematic events (e.g., hangs or gear malfunction) that could have influenced fishing efficiency (i.e., catch). All paired tows were performed on 9 commercial shrimp vessels equipped with bottom otter trawls (3 vessels in 2015, 2 vessels in 2016, and 4 vessels in 2017). During the trials in 2015 and 2016, all vessels were greater than $12 \mathrm{~m}$ long and were rigged with 4 trawl nets (double rigged) (Figs. 1 and 2), and the vessels from which trials were conducted in 2017 ranged from $10.5 \mathrm{~m}$ to $18 \mathrm{~m}$ in length and were rigged with 2 trawl nets (twin rigged). The control and experimental nets were tested in the outside positions on double-rigged vessels, and trials conducted on double-rigged vessels

\footnotetext{
${ }^{11}$ NMFS (National Marine Fisheries Service). 2016. Bycatch reduction device testing manual, 8 p. Southeast Reg. Off., Natl. Mar. Fish. Serv., NOAA, St. Petersburg, FL. [Available from website.]
} 


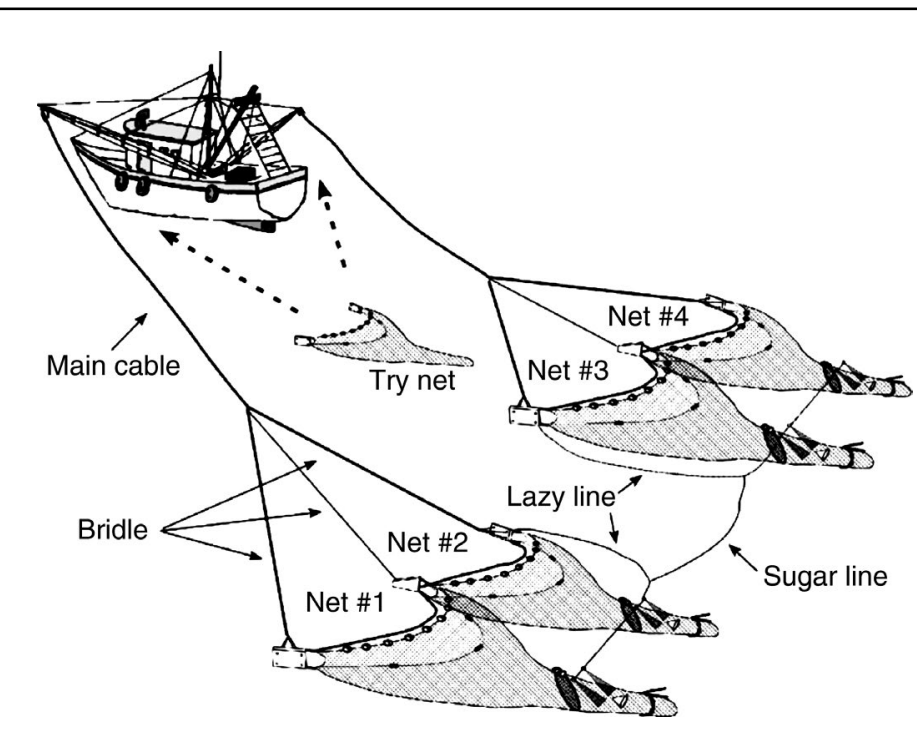

Figure 1

Illustration of a typical shrimp vessel equipped with 4 trawl nets. Double-rigged vessels like this one were used during the trials conducted in 2015 and 2016 in Pamlico Sound, North Carolina. Control and experimental gear were placed in the outside positions (i.e., Net \#1 or Net \#4). Note that try nets were not used in this study. Image source: Scott-Denton et al. (2012).

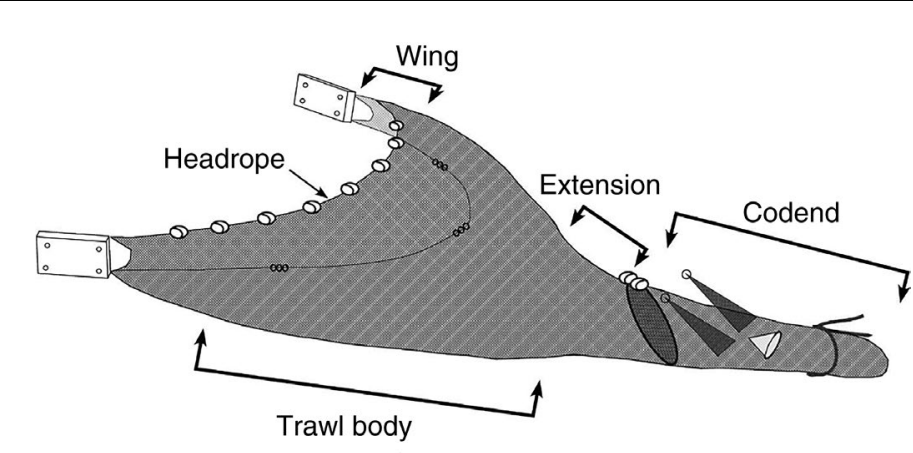

Figure 2

Illustration of the components of a trawl net. Several modifications of the trawl net typically used in the shrimp fishery were tested for this study aboard commercial vessels in Pamlico Sound and nearshore waters off North Carolina during 2015-2017. Image source: Scott-Denton et al. (2012).

minimized or eliminated the use of try nets to mitigate potential effects from their use (Eayrs, 2012; Figs. 1 and 2). To coincide with the peak shrimp seasons, testing was conducted during June-July 2015, July-September 2016, and July 2017 in Pamlico Sound and from August through November 2017 in the nearshore waters of North Carolina (Fig. 3). All paired tows were performed under normal fishing conditions.

Observers were hired and trained to collect data under NCDMF protocols and met or exceeded National Marine
Fisheries Service (NMFS) guidelines $\left(\mathrm{NMFS}^{12}\right)$. Two observers were assigned to each trial. Personnel from the Beaufort Laboratory, NOAA Southeast Fisheries Science Center, trained observers to handle, transport, identify, resuscitate, tag, and release protected sea turtles in accordance with federal standards of the U.S. Endangered Species Act.

Prior to formal field trials, tows were made to calibrate the nets on each side of the vessel to ensure that the nets fished evenly. To reduce the potential for side bias, protocol required that experimental and control modifications be switched periodically from one side to the other side to achieve an equal number of successful tows on each side of the vessel. Specifically, only the gear modifications being tested (i.e., BRDs and TEDs with reduced bar spacing) were switched while the body of the net remained to mitigate any net effect. Gear specification data were collected for both experimental and control nets and included fabrication costs, head rope length, mesh size of wing and codend, TED type, TED bar spacing, BRD type, and location, duration, and time of day of tow.

At the request of industry collaborators, data were collected for whole hauls (i.e., catches were not subsampled). Specifically, industry collaborators were concerned about the public perception of sampling a portion of the catch versus obtaining a census of harvest from each tow. Following each paired tow, the catches from each net (experimental and control) were counted and weighed separately in their entirety. Because of the volume of catch, organisms were not identified to species; instead, catches were grouped into shrimp and finfish categories for counting and weighing. In 2015, the total weight (in kilograms) of shrimp and finfish were recorded. In 2016 and 2017, smaller catches allowed further categorization that included groups for penaeid shrimp, finfish, non-shrimp invertebrates, sharks and rays, and miscellaneous organisms.

\section{Description of control and experimental gears}

All control and experimental nets were built to have identical head rope length, footrope length, and net bodies. The control net configuration for this project consisted of a shrimp otter bottom (2-seam) trawl with a state fisheye, a TED with $10.16-\mathrm{cm}$ bar spacing, and a 3.81-cm stretched mesh codend (Fig. 4). This configuration was considered the most typical gear

\footnotetext{
${ }^{12}$ NMFS (National Marine Fisheries Service). 2010. Characterization of the US Gulf of Mexico and southeastern Atlantic otter trawl and bottom reef fish fisheries: observer training manual, 186 p. Galveston Lab., Southeast Fish. Sci. Cent., Natl. Mar. Fish. Serv., NOAA, Galveston, TX. [Available from website.]
} 


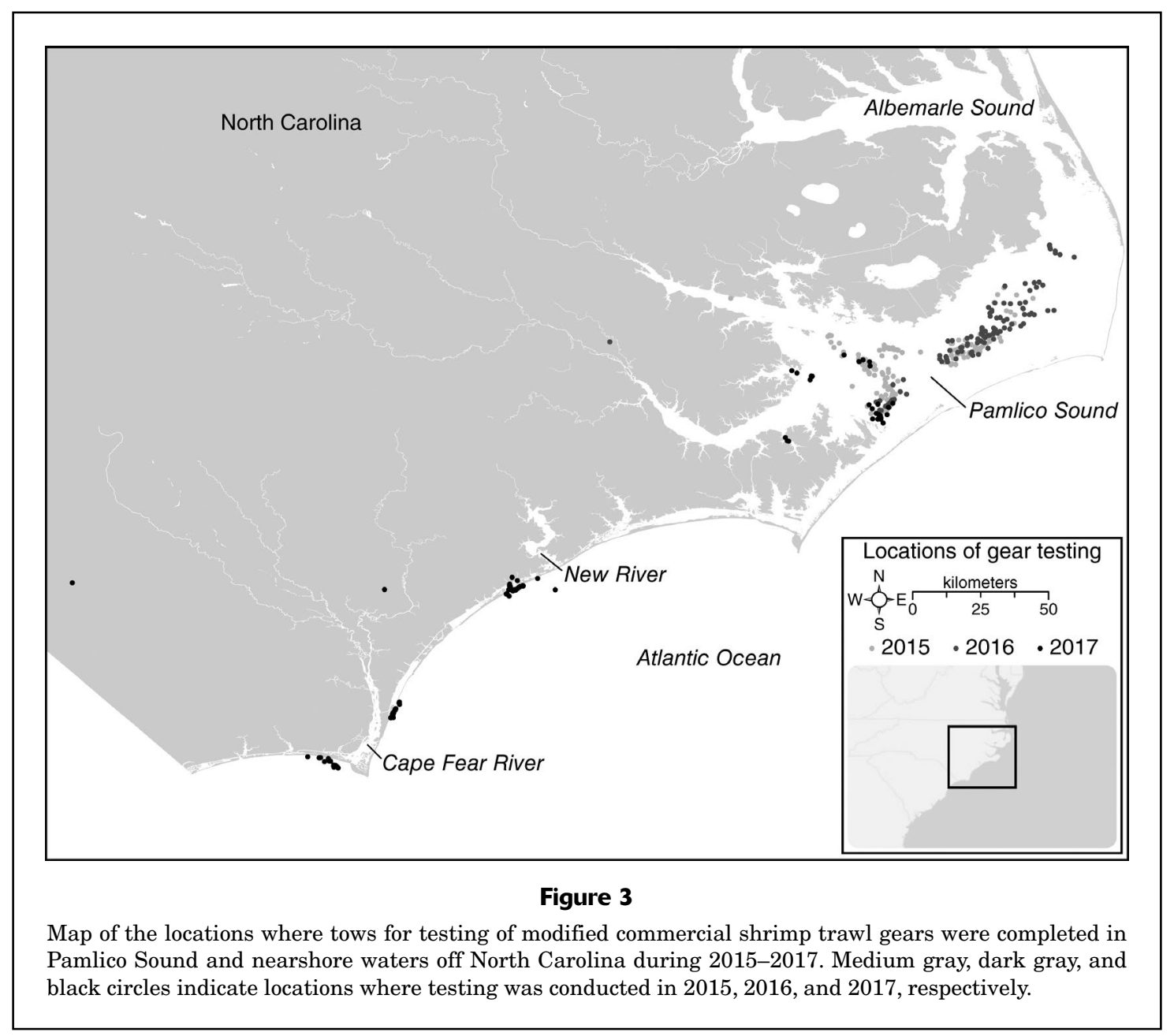

configuration used by the industry at the time of the start of this study and was dictated by the NCMFC's preferred management strategy.

The type, shape, frame size, and cover type (double or single) of TEDs were standardized on each test vessel. The orientation, either top or bottom, was identical for both control and test TEDs on each vessel; however, both bottom-opening and top-opening TEDs were tested throughout the study. Bar spacing of TEDs varied among control and experimental configurations as indicated in the next paragraph.

Five experimental gear configurations were tested in 2015, 4 configurations were tested in 2016, and 5 configurations were tested in 2017 (Table 1, Fig. 4). The first BRD tested in 2015 was a federally certified (by NOAA) composite panel with a fish spooker cone (Table 1, Fig. 4). This gear consists of 2 composite panels installed in the lower part of the extension. The panels taper inward, creating an area with slow water flow that allows escape of fish through 2 triangular openings. Each composite panel is composed of 2 overlapping panels, a diamond mesh panel and a square mesh panel. The diamond mesh panel reduces the water flow, and the square mesh panel provides support, preventing obstruction of the escape openings $\left(\mathrm{NMFS}^{13}\right)$. This net was also equipped with a single state fisheye. The next gear tested was equipped with a TED with reduced, 7.62-cm bar spacing (hereafter referred to as reduced-bar $T E D$ ) (Table 1, Fig. 4). However, following a week of testing with this gear during which less than desired reductions in finfish bycatch were observed, the trial was terminated. The next gear tested was equipped with a reduced-bar TED and included a square mesh panel (on the codend) and a larger 4.76-cm stretch mesh codend (Table 1, Fig. 4). The square mesh panel was constructed of 8.89-cm stretch mesh and was 5 meshes wide and 12 meshes long. This net was also equipped with a single state fisheye.

The fourth gear tested in 2015 was the Ricky BRD (Fig. 4), which is composed of a pair of diamond-shaped, federal fisheye BRDs (each with a $258-\mathrm{cm}^{2}$ opening) (hereafter referred to as federal fisheye) with a float

\footnotetext{
${ }^{13}$ NMFS (National Marine Fisheries Service). 2008. Recommended construction and installation instructions for the composite panel bycatch reduction device, 8 p. Harvest. Syst. Eng. Branch, Natl. Mar. Fish. Serv., NOAA, Pascagoula, MS. [Available from website.]
} 


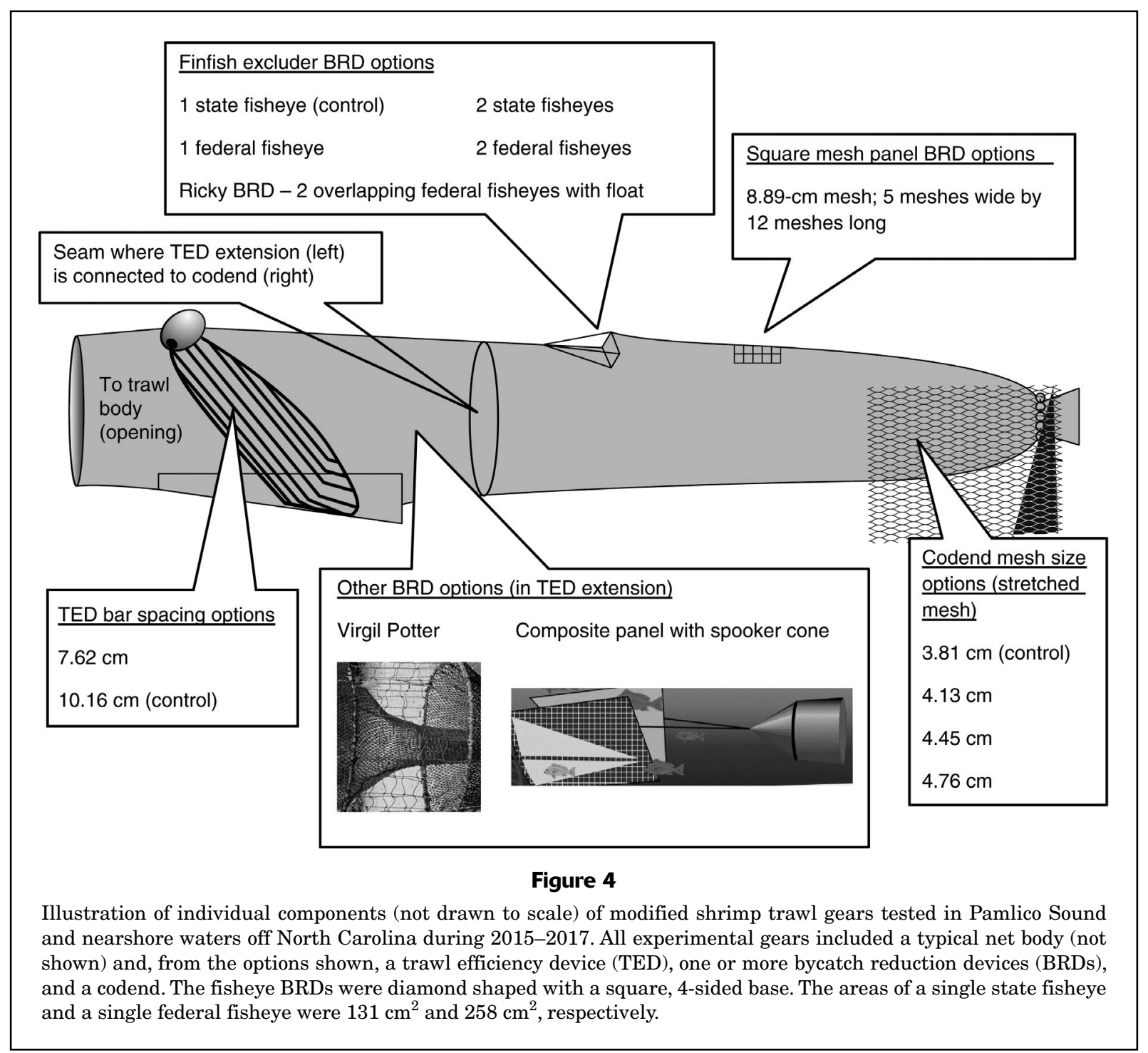

(Helies et al. ${ }^{14}$ ). The first federal fisheye BRD was installed $3.05 \mathrm{~m}$ from the codend tie-off rings. A second federal fisheye was installed $30 \mathrm{~cm}$ forward of the first federal fisheye, so that the aft of the forward fisheye touched the forward section of the aft fisheye. A $20.3-\mathrm{cm}$, hard plastic float was placed inside the codend, just forward of the tip of the most forward fisheye. The gear was tested and yielded less than satisfactory results; therefore, the trial was terminated. The next gear tested was designed with double federal fisheyes placed in the position required by North Carolina Division of Marine Fisheries: the first fisheye

\footnotetext{
${ }^{14}$ Helies, F., J. Jamison, and B. Gallaway. 2015. Continued development and assessment of bycatch reduction devices within the southeastern shrimp trawl fishery, $36 \mathrm{p}$. Final report to the National Oceanic and Atmospheric Administration National Marine Fisheries for NOAA Award NA10NMF4540108 (GSAFFI \#115). [Available from Gulf and South Atlantic Fish. Found. Inc., Ste. 997, Lincoln Cent., 5401 W. Kennedy Blvd., Tampa, FL 33609.]
}

was placed 68 meshes forward of tie-off rings, and the second fisheye was placed 5 meshes forward of the forward edge of the first fisheye. In addition, the codend mesh size was increased to $4.76 \mathrm{~cm}$ (Table 1, Fig. 4).

Four gears were tested in 2016. The first gear was composed of 1 state fisheye and the Virgil Potter BRD (Table 1, Fig. 4). This gear consisted of a radial escape section constructed of $21.6-\mathrm{cm}$ stretch mesh that was 5 meshes long. A funnel constructed of 3.81-cm stretch mesh was also part of this design. The next BRD tested included 2 federal fisheyes in the state-required position (as described previously) and a 4.45-cm stretch mesh codend (Table 1, Fig. 4). The next BRD combination tested included a reduced-bar TED, double federal fisheyes in the state-required position (as described previously), and a 4.45-cm stretch mesh codend (Table 1, Fig. 4). The final gear tested in 2016 was the Virgil Potter BRD with 1 state fisheye and a $4.45-\mathrm{cm}$ stretch mesh codend (Table 1, Fig. 4). 
In the summer of 2017,3 experimental gears were tested, with each including a reduced-bar TED, 1 state fisheye, and a 3.81-cm codend (Table 1, Fig. 4). Following 5 paired tows with less than desired reductions of finfish bycatch observed, the experimental gear in the trial was changed to include a reduced-bar TED, 1 state fisheye, and a $4.13-\mathrm{cm}$ stretch mesh codend (Table 1, Fig. 4). The next tested gear, in the summer of 2017, was a reducedbar TED with 2 state fisheyes and a $4.13-\mathrm{cm}$ stretch mesh codend (Table 1, Fig. 4). In the autumn of 2017, 2 experimental gears were tested. The first included a reduced-bar TED, 2 state fisheyes, and a 4.13-cm stretch mesh codend (Table 1, Fig. 4). Finally, a modification of that gear, consisting of a reduced-bar TED, 2 federal fisheyes, and a $4.13-\mathrm{cm}$ stretch mesh codend, was tested (Table 1, Fig. 4).

\section{Analyses}

Any problematic tows (as described previously) were dropped. Catch per unit of effort (CPUE) was calculated as weight divided by tow time; observed weights were standardized to either a 2-h tow time (2015-2016) or a 1-h tow time (2017) to adjust for differences in tow times. The CPUE values were calculated with the assumption that there were no differences in spread ratio between trawls with various BRD and TED configurations. The 1-h tow time was used in 2017 because of the smaller vessel and net size. The average weight of catch was computed for each gear (control and experimental) and taxonomic group along with the differences in average weight of catch and percent change in CPUE.

Paired $t$-tests were used to evaluate any differences in average CPUE values between the control and experimental nets by using the SURVEYSELECT procedure in the software SAS 9.4 ${ }^{15}$ (SAS Institute Inc., Cary, NC). The null hypothesis for the $t$-test was that there was no difference in CPUE between the control and experimental nets (significance level of 0.05). The procedure was used to account for any uneven number of tows by gear type per vessel side made during trials and to randomly select an even number of tows to minimize side-bias. This procedure resulted in the random exclusion of tows for some analyses.

One of the assumptions of the $t$-test is that the dependent variable (in this case, CPUE) is normally distributed within each group. Because ecological data are often non-normal, a second test that does not require normality of the data distribution was applied to the data. Specifically, a randomization procedure (Manly, 2007) was also used to compare CPUE between control and experimental nets for each gear and taxonomic group. The null hypothesis for the randomization test was that there was no difference in CPUE between the control and experimental nets. The test statistic evaluated was

\footnotetext{
${ }^{15}$ Mention of trade names or commercial companies is for identification purposes only and does not imply endorsement by the National Marine Fisheries Service, NOAA.
}

the difference in average CPUE between the control and experimental nets. Data were randomized and resampled 10,000 times for each gear and taxonomic group. The $P$-value from the randomization test for a 2 -tailed test was the proportion of test statistics (including those computed from the original data) that were as large or larger in absolute value than the absolute value of the statistic computed from the original data. Code for this test was written and run in the $\mathrm{R}$ statistical program (vers. 3.4.3; R Core Team, 2017).

\section{Results}

A total of 412 paired tows were made by using 14 experimental gear configurations. Testing occurred on 39 trips across 104 fishing days by a total of 9 different industry fishing vessels. A trip was defined as the time period that began when a vessel departed port to conduct fishing operations and ended with a return to port. Observers sampled and weighed over $142,000 \mathrm{~kg}$ of fish, shrimp, and other marine organisms. An even number of tows by side of vessel was not achieved for most gears (Table 2), and $81 \%$ of paired tows were made during the day (Table 2). The results of both the paired $t$-tests and the randomization tests for testing completed from 2015 through 2017 can be found in Tables $3-5$.

\section{Paired $t$-tests}

None of the 5 experimental gears tested in 2015 lost a significant amount of shrimp ( $P>0.05$; Table 3$)$. Only with the Ricky BRD did we fail to achieve a significant reduction in finfish bycatch compared with that achieved by using the control gear (6.6\% reduction with Ricky $\mathrm{BRD}, P=0.503$ ). However, testing of this gear was discontinued after only 15 tows. Only by using the configuration with double federal fisheyes and a $4.76-\mathrm{cm}$ codend was a greater than $40 \%$ reduction in bycatch $(40.8 \%)$ achieved while maintaining shrimp catch (1.0\% gain).

In 2016, no significant shrimp loss was observed during tows of the 4 gears tested (Table 4 ). With the Virgil Potter gear, we achieved a significant gain in shrimp harvest over that during tests with the control net (9.9\% gain, $P=0.050$ ). Significant reduction in finfish bycatch was observed with the use of all test BRDs in 2016, and the use of 3 of the 4 gears resulted in bycatch reduction in excess of the $40 \%$ target in a range of $43-57 \%$.

In 2017, 1 of the 5 gears tested was not analyzed by using the $t$-test, because of low sample size. When 3 of the remaining 4 gears were tested in 2017, significant shrimp loss was observed (Table 5). Tests of the gear with a reduced-bar TED, double state fisheyes, and a $4.13-\mathrm{cm}$ codend during summer, the gear with a reduced-bar TED, double state fisheyes, and a 4.13-cm codend during autumn, and the gear with a reduced-bar TED, double federal fisheyes, and a 4.13-cm codend resulted in shrimp losses of $6.8 \%, 14.9 \%$, and $9.0 \%$, respectively. By using 2 of these gears, the reducedbar TED with a 4.13-cm codend and the reduced-bar TED 


\section{Table 2}

Number of port and starboard tows made with control and experimental gears in Pamlico Sound in June and July 2015, July-September 2016, and July 2017 and in nearshore waters off North Carolina in August-November 2017. Some of the gears had trawl efficiency devices (TEDs) with reduced bar spacing, and bycatch reduction devices (BRDs) included the Ricky BRD, Virgil Potter BRD, and state and federal fisheyes. An asterisk (*) indicates that 1 tow made with this gear configuration was dropped from analysis.

\begin{tabular}{|c|c|c|c|c|}
\hline \multirow[b]{2}{*}{ Year } & \multirow[b]{2}{*}{ Gear description } & \multirow[b]{2}{*}{ Net } & \multicolumn{2}{|c|}{ Number of tows } \\
\hline & & & Port & Starboard \\
\hline \multirow{10}{*}{2015} & \multirow{2}{*}{ Composite panel } & Control & 37 & 22 \\
\hline & & Experimental & 22 & 37 \\
\hline & \multirow[t]{2}{*}{ Reduced-bar TED } & Control & 10 & 9 \\
\hline & & Experimental & 9 & 10 \\
\hline & \multirow[t]{2}{*}{ Reduced-bar TED + square mesh panel + 4.76-cm codend } & Control & 31 & 20 \\
\hline & & Experimental & 20 & 31 \\
\hline & \multirow[t]{2}{*}{ Ricky BRD } & Control & 10 & 5 \\
\hline & & Experimental & 5 & 10 \\
\hline & \multirow[t]{2}{*}{ Double federal fisheyes +4.76 -cm codend* } & Control & 19 & 13 \\
\hline & & Experimental & 14 & 19 \\
\hline \multirow{8}{*}{2016} & \multirow{2}{*}{ Virgil Potter BRD } & Control & 18 & 15 \\
\hline & & Experimental & 15 & 18 \\
\hline & \multirow[t]{2}{*}{ Double federal fisheyes $+4.45-\mathrm{cm}$ codend } & Control & 20 & 3 \\
\hline & & Experimental & 3 & 20 \\
\hline & \multirow{2}{*}{ Reduced-bar TED + double federal fisheyes + 4.45-cm codend } & Control & 15 & 15 \\
\hline & & Experimental & 15 & 15 \\
\hline & \multirow[t]{2}{*}{ Virgil Potter BRD + 4.45-cm codend } & Control & 11 & 14 \\
\hline & & Experimental & 14 & 11 \\
\hline \multirow{10}{*}{2017} & \multirow{2}{*}{ Reduced-bar TED } & Control & 5 & 5 \\
\hline & & Experimental & 5 & 5 \\
\hline & \multirow[t]{2}{*}{ Reduced-bar TED + 4.13-cm codend } & Control & 10 & 15 \\
\hline & & Experimental & 15 & 10 \\
\hline & \multirow[t]{2}{*}{ Reduced-bar TED + double state fisheyes + 4.13-cm codend (summer) } & Control & 15 & 15 \\
\hline & & Experimental & 15 & 15 \\
\hline & \multirow[t]{2}{*}{ Reduced-bar TED + double state fisheyes + 4.13-cm codend (autumn) } & Control & 15 & 15 \\
\hline & & Experimental & 15 & 15 \\
\hline & \multirow[t]{2}{*}{ Reduced-bar TED + double federal fisheyes $+4.13-\mathrm{cm}$ codend } & Control & 15 & 15 \\
\hline & & Experimental & 15 & 15 \\
\hline
\end{tabular}

with double state fisheyes and a 4.13-cm codend that was tested in summer, we achieved significant bycatch reduction ( $22.8 \%, P=0.019$, and $32.6 \%, P<0.001$, respectively), although we did not obtain the desired $40 \%$ reduction.

\section{Randomization tests}

In the randomization tests, no significant loss of shrimp catch was observed among the 5 gears tested in 2015 (Table 3). Significant $(P<0.05)$ decreases in finfish catch were found in all gears tested in 2015 except for the reduced-bar TED and Ricky BRD. Of the gears for which a significant reduction in finfish CPUE was detected, only the use of the double federal fisheye with a $4.76-\mathrm{cm}$ codend resulted in a reduction greater than the target of $40 \%$ $(40.1 \%, P<0.001)$.

No significant loss of shrimp catch was detected for the 4 gears tested in 2016, on the basis of the results of the randomization tests (Table 4). Tests with all 4 gears resulted in a significant $(P<0.05)$ decrease in the catch of finfish. The use of the double federal fisheye (54.0\%), the reduced-bar TED with a double federal fisheye and a 4.45-cm codend (44.9\%), and the Virgil Potter BRD with a $4.45-\mathrm{cm}$ codend $(44.3 \%)$ all resulted in reductions greater than the $40 \%$ target. According to the results of the randomization tests, no significant changes were detected in the CPUE of invertebrates or elasmobranchs in 2016.

None of the 5 gears tested in 2017 had a significant loss of shrimp catch, on the basis of the results of the randomization tests (Table 5). Only when the gear with a reducedbar TED, double state fisheyes, and a 4.13-cm codend was tested in summer was a significant decrease in finfish catch $(32.6 \%)$ observed, although the decrease was less than the $40 \%$ target. Significant decreases in the catches of invertebrates (65.1\%) and elasmobranchs (57.3\%) were achieved when the gear with the reduced-bar TED, 


\section{Table 3}

Results of the paired $t$-tests and randomization tests used to compare catch per unit of effort (CPUE), weight divided by tow time, between the control gear and 5 experimental (Exp.) gears tested in 2015 in Pamlico Sound, North Carolina. Some of the gears had trawl efficiency devices (TEDs) with reduced bar spacing, and bycatch reduction devices (BRDs) included a composite panel, the Ricky BRD, and a federal fisheye. Mean values of CPUE are reported in kilograms. $n=$ number of tows.

\begin{tabular}{|c|c|c|c|c|c|c|c|c|c|c|c|}
\hline \multirow[b]{2}{*}{ Gear } & \multirow[b]{2}{*}{$\begin{array}{l}\text { Taxonomic } \\
\text { group }\end{array}$} & \multirow[b]{2}{*}{$n$} & \multirow{2}{*}{$\frac{\text { Control }}{}$} & \multirow{2}{*}{$\begin{array}{l}\text { Exp. } \\
\text { Mean }\end{array}$} & \multicolumn{2}{|c|}{$t$-test } & \multirow[b]{2}{*}{$n$} & \multirow{2}{*}{$\frac{\text { Control }}{\text { Mean }}$} & \multirow{2}{*}{$\begin{array}{l}\text { Exp. } \\
\text { Mean }\end{array}$} & \multicolumn{2}{|c|}{ Randomization } \\
\hline & & & & & $\begin{array}{c}\text { Change } \\
(\%)\end{array}$ & $P$-value & & & & $\begin{array}{c}\text { Change } \\
(\%)\end{array}$ & $P$-value \\
\hline \multirow[t]{2}{*}{ Composite panel } & Finfish & 44 & 178.1 & 132.1 & -25.83 & $<0.001$ & 60 & 177.3 & 128.4 & -27.60 & $<0.001$ \\
\hline & Shrimp & 44 & 64.3 & 63.9 & -0.65 & 0.754 & 60 & 67.3 & 65.2 & -3.13 & 0.776 \\
\hline \multirow[t]{2}{*}{ Reduced-bar TED } & Finfish & 16 & 107.3 & 70.0 & -16.18 & 0.029 & 19 & 112.8 & 89.8 & -20.40 & 0.217 \\
\hline & Shrimp & 16 & 49.6 & 46.0 & -7.35 & 0.078 & 19 & 48.2 & 45.5 & -5.63 & 0.739 \\
\hline \multirow{2}{*}{$\begin{array}{l}\text { Reduced-bar TED + square mesh panel + } \\
4.76-\mathrm{cm} \text { codend }\end{array}$} & Finfish & 40 & 104.8 & 78.2 & -25.34 & $<0.001$ & 51 & 102.3 & 74.1 & -27.50 & 0.007 \\
\hline & Shrimp & 40 & 65.7 & 64.4 & -1.94 & 0.309 & 51 & 67.3 & 65.2 & -3.04 & 0.775 \\
\hline \multirow[t]{2}{*}{ Ricky BRD } & Finfish & 10 & 110.6 & 103.3 & -6.61 & 0.503 & 15 & 100.0 & 95.5 & -4.55 & 0.793 \\
\hline & Shrimp & 10 & 35.3 & 31.8 & -9.87 & 0.449 & 15 & 35.4 & 33.3 & -6.06 & 0.728 \\
\hline \multirow[t]{2}{*}{ Double federal fisheyes $+4.76-\mathrm{cm}$ codend } & Finfish & 25 & 90.0 & 53.3 & -40.81 & $<0.001$ & 32 & 88.3 & 52.9 & -40.10 & $<0.001$ \\
\hline & Shrimp & 25 & 61.3 & 61.9 & 1.00 & 0.778 & 32 & 60.6 & 61.9 & 2.16 & 0.862 \\
\hline
\end{tabular}

\section{Table 4}

Results of the paired $t$-tests and randomization tests used to compare catch per unit of effort (CPUE), weight divided by tow time, between the control gear and 4 experimental (Exp.) gears tested in 2016 in Pamlico Sound, North Carolina. One of the gears had a trawl efficiency device (TED) with reduced bar spacing, and bycatch reduction devices included the Virgil Potter and federal fisheye. Mean values of CPUE are reported in kilograms. Values for invertebrates are for all non-commercial shrimp invertebrates. $n=$ number of tows.

\begin{tabular}{|c|c|c|c|c|c|c|c|c|c|c|c|}
\hline \multirow[b]{2}{*}{ Gear } & \multirow[b]{2}{*}{$\begin{array}{l}\text { Taxonomic } \\
\text { group }\end{array}$} & \multirow[b]{2}{*}{$n$} & \multirow{2}{*}{$\begin{array}{l}\text { Control } \\
\text { Mean }\end{array}$} & \multirow{2}{*}{$\begin{array}{l}\text { Exp. } \\
\text { Mean }\end{array}$} & \multicolumn{2}{|c|}{$t$-test } & \multirow[b]{2}{*}{$n$} & \multirow{2}{*}{$\begin{array}{l}\text { Control } \\
\text { Mean }\end{array}$} & \multirow{2}{*}{$\begin{array}{l}\text { Exp. } \\
\text { Mean }\end{array}$} & \multicolumn{2}{|c|}{ Randomization } \\
\hline & & & & & $\begin{array}{c}\text { Change } \\
(\%)\end{array}$ & $P$-value & & & & $\begin{array}{c}\text { Change } \\
(\%)\end{array}$ & $P$-value \\
\hline \multirow[t]{4}{*}{ Virgil Potter } & Finfish & 30 & 146.3 & 106.9 & -26.92 & $<0.001$ & 33 & 149.4 & 106.9 & -28.50 & 0.005 \\
\hline & Shrimp & 30 & 62.6 & 68.8 & 9.92 & 0.050 & 33 & 61.8 & 67.0 & 8.51 & 0.696 \\
\hline & Invertebrates & 10 & 3.3 & 2.7 & -18.79 & 0.384 & 33 & 1.0 & 0.8 & -18.80 & 0.681 \\
\hline & Elasmobranchs & 7 & 5.3 & 5.9 & 11.11 & 0.589 & 33 & 1.1 & 1.2 & 11.10 & 0.912 \\
\hline \multirow{4}{*}{$\begin{array}{l}\text { Double federal fisheye }+ \\
\text { 4.45-cm codend }\end{array}$} & Finfish & 6 & 201.5 & 86.3 & -57.19 & 0.001 & 23 & 164.5 & 75.6 & -54.00 & $<0.001$ \\
\hline & Shrimp & 6 & 23.0 & 20.2 & -12.11 & 0.215 & 23 & 28.1 & 23.6 & -16.20 & 0.280 \\
\hline & Invertebrates & 6 & 7.2 & 6.1 & -15.67 & 0.081 & 23 & 5.4 & 5.1 & -4.85 & 0.833 \\
\hline & Elasmobranchs & 6 & 1.8 & 2.6 & 45.79 & 0.509 & 23 & 2.1 & 2.5 & 18.80 & 0.573 \\
\hline \multirow{4}{*}{$\begin{array}{l}\text { Reduced-bar TED + double fed- } \\
\text { eral fisheye }+4.45-\mathrm{cm} \text { codend }\end{array}$} & Finfish & 30 & 115.4 & 63.6 & -44.91 & $<0.001$ & 30 & 115.4 & 63.6 & -44.90 & 0.007 \\
\hline & Shrimp & 30 & 27.0 & 25.7 & -4.85 & 0.435 & 30 & 27.0 & 25.7 & -4.85 & 0.706 \\
\hline & Invertebrates & 30 & 2.1 & 1.8 & -13.26 & 0.418 & 30 & 2.1 & 1.8 & -13.30 & 0.601 \\
\hline & Elasmobranchs & 27 & 1.8 & 1.4 & -18.62 & 0.404 & 30 & 1.6 & 1.3 & -18.60 & 0.568 \\
\hline \multirow[t]{2}{*}{ Virgil Potter + 4.45-cm codend } & Finfish & 22 & 189.1 & 107.4 & -43.20 & $<0.001$ & 25 & 172 & 96.1 & -44.30 & 0.001 \\
\hline & Shrimp & 22 & 33.2 & 31.3 & -5.46 & 0.055 & 25 & 31.3 & 29.5 & -5.78 & 0.691 \\
\hline
\end{tabular}

double state fisheyes, and a 4.13 -cm codend was tested in autumn; however, the observed catches were relatively small.

\section{Test comparison}

A comparison of the results from the paired $t$-tests and randomization tests (relative to the results of each other and to the raw data as collected) is provided in Tables 3-5.
In general, both tests produced similar results. A paired $t$-test detected a significant decrease in finfish CPUE for the reduced-bar TED (tested in 2015) and the reduced-bar TED with a 4.13-cm codend (tested in 2017), whereas the results of the randomization tests indicate no significant difference in finfish bycatch between these gears (Tables 3 and 5). Additionally, a paired $t$-test detected a significant increase in shrimp catch for the Virgil Potter gear (tested in 2016), but in a randomization test, no significant change 


\section{Table 5}

Results of the paired $t$-tests and randomization tests used to compare catch per unit of effort (CPUE), weight divided by tow time, between the control gear and 5 experimental (Exp.) gears tested in 2017 in Pamlico Sound and nearshore waters off North Carolina. Each of the 5 gears had a trawl efficiency device (TED) with reduced bar spacing, and bycatch reduction devices included state and federal fisheyes. Mean values of CPUE are reported in kilograms. An asterisk $(*)$ indicates that data for a taxonomic group were not analyzed with a $t$-test because of low sample size. Values for invertebrates are for all non-commercial shrimp invertebrates. $n=$ number of tows.

\begin{tabular}{|c|c|c|c|c|c|c|c|c|c|c|c|}
\hline \multirow[b]{2}{*}{ Gear } & \multirow[b]{2}{*}{$\begin{array}{l}\text { Taxonomic } \\
\text { group }\end{array}$} & \multirow[b]{2}{*}{$n$} & \multirow{2}{*}{$\begin{array}{l}\text { Control } \\
\text { Mean }\end{array}$} & \multirow{2}{*}{$\begin{array}{l}\text { Exp. } \\
\text { Mean }\end{array}$} & \multicolumn{2}{|c|}{$t$-test } & \multirow[b]{2}{*}{$n$} & \multirow{2}{*}{$\frac{\text { Control }}{\text { Mean }}$} & \multirow{2}{*}{$\begin{array}{l}\text { Exp. } \\
\text { Mean }\end{array}$} & \multicolumn{2}{|c|}{ Randomization } \\
\hline & & & & & $\begin{array}{c}\text { Change } \\
(\%)\end{array}$ & $P$-value & & & & $\begin{array}{c}\text { Change } \\
(\%)\end{array}$ & $P$-value \\
\hline \multirow[t]{4}{*}{ Reduced-bar TED } & Finfish & * & $*$ & $*$ & $*$ & $*$ & 5 & 12.3 & 12.9 & 5.06 & 0.732 \\
\hline & Shrimp & $*$ & $*$ & $*$ & $*$ & $*$ & 5 & 18.7 & 17.3 & -7.79 & 0.827 \\
\hline & Invertebrates & $*$ & $*$ & $*$ & $*$ & $*$ & 5 & 4.9 & 6.8 & 38.78 & 0.281 \\
\hline & Elasmobranchs & * & $*$ & $*$ & $*$ & $*$ & 4 & 0.2 & 0.4 & 75.00 & 0.487 \\
\hline \multirow[t]{4}{*}{ Reduced-bar TED + 4.13-cm codend } & Finfish & 20 & 34.6 & 26.7 & -22.80 & 0.019 & 22 & 34.9 & 27.8 & -20.42 & 0.341 \\
\hline & Shrimp & 20 & 12.1 & 11.2 & -7.82 & 0.294 & 22 & 11.6 & 10.6 & -9.04 & 0.556 \\
\hline & Invertebrates & 18 & 2.3 & 2.1 & -6.06 & 0.692 & 22 & 2.07 & 2.06 & -0.444 & 0.993 \\
\hline & Elasmobranchs & $*$ & $*$ & $*$ & $*$ & $*$ & 3 & 0.3 & 0.1 & -80.00 & 0.397 \\
\hline \multirow{4}{*}{$\begin{array}{l}\text { Reduced-bar TED + double state } \\
\text { fisheyes }+4.13-\mathrm{cm} \text { codend } \\
\text { (summer })\end{array}$} & Finfish & 30 & 146.0 & 98.5 & -32.60 & $<0.001$ & 30 & 146.0 & 98.5 & -32.61 & 0.002 \\
\hline & Shrimp & 30 & 2.9 & 2.7 & -6.80 & 0.039 & 30 & 2.9 & 2.7 & -6.64 & 0.598 \\
\hline & Invertebrates & 30 & 17.2 & 15.9 & -7.58 & 0.086 & 30 & 17.2 & 15.9 & -7.59 & 0.505 \\
\hline & Elasmobranchs & 29 & 3.0 & 2.5 & -16.3 & 0.184 & 30 & 2.87 & 2.4 & -16.70 & 0.425 \\
\hline \multirow{4}{*}{$\begin{array}{l}\text { Reduced-bar TED + double st } \\
\text { fisheyes + 4.13-cm codend } \\
\text { (autumn) }\end{array}$} & Finfish & 30 & 57.5 & 54.9 & -4.57 & 0.670 & 30 & 57.5 & 54.9 & -4.58 & 0.890 \\
\hline & Shrimp & 30 & 9.8 & 8.3 & -14.90 & $<0.001$ & 30 & 9.75 & 8.3 & -14.83 & 0.365 \\
\hline & Invertebrates & 30 & 8.2 & 2.9 & -65.10 & 0.001 & 30 & 8.20 & 2.9 & -65.07 & $<0.001$ \\
\hline & Elasmobranchs & 28 & 4.4 & 1.9 & -57.10 & 0.009 & 29 & 4.26 & 1.8 & -57.29 & 0.014 \\
\hline \multirow{4}{*}{$\begin{array}{l}\text { Reduced-bar TED + double federal } \\
\text { fisheyes + 4.13-cm codend }\end{array}$} & Finfish & 30 & 75.6 & 97.7 & 29.30 & 0.204 & 30 & 75.6 & 97.7 & 29.30 & 0.250 \\
\hline & Shrimp & 30 & 17.3 & 15.7 & -9.04 & 0.002 & 30 & 17.3 & 15.1 & -12.48 & 0.234 \\
\hline & Invertebrates & 25 & 2.2 & 2.7 & 21.90 & 0.276 & 30 & 2.29 & 2.9 & 25.15 & 0.455 \\
\hline & Elasmobranchs & 15 & 1.3 & 1.0 & -24.30 & 0.271 & 28 & 0.904 & 0.7 & -24.50 & 0.360 \\
\hline
\end{tabular}

was found when this gear was used (Table 4). The paired $t$-test results indicate a significant decrease in shrimp catch for the gear with a reduced-bar TED, double state fisheyes, and a 4.13-cm codend that was tested in summer, the gear with a reduced-bar TED, double state fisheyes, and a 4.13-cm codend that was tested in autumn, and the gear with a reduced-bar TED, double federal fisheyes, and a 4.13-cm codend (all tested in 2017), whereas results of the randomization tests indicate no significant difference in shrimp CPUE for these gears (Table 5).

The results of both tests indicate that the double federal fisheye with a 4.76-cm codend (tested in 2015), the double federal fisheye with a $4.45-\mathrm{cm}$ codend (tested in 2016), the gear with a reduced-bar TED, double federal fisheye, and a 4.45-cm codend (tested in 2016), and the Virgil Potter BRD with a 4.45-cm codend (tested in 2016) exceeded the target of $40 \%$ reduction in finfish bycatch (Tables 3-5). None of those gears had a significant decrease in shrimp catches in either the paired $t$-tests or randomization tests.

\section{Gear costs}

Relative to the material and labor costs associated with constructing a single control trawl (\$3000), additional costs associated with modifying the control gear to that of each experimental gear ranged from $\$ 110$ to $\$ 1250$ (Table 1). An additional $\$ 600$ per trawl above the cost of a typical control net was the minimum investment required to achieve reduction $>40 \%$ in finfish bycatch in this study.

\section{Discussion}

\section{Gear performance}

The goal to achieve a reduction of $40 \%$ in finfish bycatch did not allow this study to evaluate the effects of single gear modifications, as is typically conducted in BRD testing (Brewer et al., 1998). However, the bycatch reduction goal was achieved by using BRD combinations chosen through a collaborative process that relied on expert opinions and past research. Four of the 14 gear combinations that were tested met the immediate project goal, and the results of this study provide direction for future testing and for making interim management recommendations (Tables 3 and 4). In fact, the NCMFC voted in May 2018 to implement these gear combinations as a requirement, beginning in 2019 on larger vessels (>12 m) fishing in 
Pamlico Sound, North Carolina $\left(\mathrm{NCDMF}^{16}\right)$. A proclamation was issued for these requirements, which went into effect by July 2019 .

Although we cannot attribute observed reductions in finfish bycatch to one element, all 4 gears that achieved the target of greater than $40 \%$ bycatch reduction (Tables $3-5$ ) used a combination of increased codend mesh size and larger finfish escape openings relative to the control configuration. The simple use of 2 federal fisheyes provided a combined opening size of $516 \mathrm{~cm}^{2}$, almost 4 times the opening of the industry-standard state fisheye $\left(131 \mathrm{~cm}^{2}\right)$. In addition to allowing larger fish to escape the trawl, the larger escape openings likely create a larger area for the flow of disturbed water, a difference that has been shown to result in higher rates of escape (Wardle, 1986; Engaas et al., 1999; Watson et al., 1999; Winger et al., 2010). The use of each of these 4 gears did not result in a significant decrease in shrimp catch relative to that from the use of the control net, but the use of the gear with the double federal fisheyes and a 4.45-cm codend produced a reduction in shrimp catch that was greater than the 5\% threshold for shrimp loss identified by workgroup members from industry (Table 4).

The use of a reduced-bar TED in several gear configurations also appears to have contributed to overall finfish bycatch reduction. The reduction of finfish bycatch achieved with this gear was more substantial after the mesh size of the codend was increased, following a weeklong trial of just a reduced-bar TED. The increase in codend mesh size may have resulted in increased water flow through the codend, allowing smaller finfish species to escape (Isaksen et al., 1992; Engaas et al., 1999).

Similar improvements in bycatch reduction from the use of reduced-bar TEDs have been found in the Gulf of Mexico (Hataway et al., 2017), Australia (Noell et al., 2018), and the nearshore waters of coastal North Carolina (Broome et al. ${ }^{17}$ ). Broome et al. ${ }^{17}$ documented that the use of a trawl equipped with a TED with 5.08-cm bar spacing and a state fisheye reduced total bycatch weight by $40 \%$ with insignificant loss of shrimp catch (6\%) in 43 paired tows conducted in nearshore waters of the Atlantic Ocean, compared with the reduction achieved with a control trawl that was similar to the control gear in this study: an otter trawl equipped with a TED with standard $10.16-\mathrm{cm}$ bar spacing and a state fisheye. Although the gear tested by Broome et al. ${ }^{17}$ met the bycatch reduction target that was set for our study, a majority of the workgroup members felt that such a reduction in TED bar spacing would not be feasible for use in the estuarine fishery because of potential

\footnotetext{
${ }^{16}$ NCDMF (North Carolina Division of Marine Fisheries). 2018. Marine Fisheries Commission briefing book for business meeting; New Bern, NC, 16-17 May, 659 p. Div. Mar. Fish., North Carolina Dep. Environ. Nat. Resour., Morehead City, NC. [Available from website.]

17 Broome, J. D., J. W. Anderson, and D. W. Anderson. 2011. Bycatch volume reduction through turtle excluder device (TED) reduced grid spacing, $37 \mathrm{p}$. Final report for North Carolina Sea Grant proj. 10-FEG-03. [Available from North Carolina Sea Grant, 303 College Circle, Morehead City, NC 28557.]
}

clogging associated with debris and grasses that are typically found in the estuarine waters of North Carolina. In fisheries outside of this test area, similar improvements in bycatch reduction have been observed when the mesh or grid size of the Nordmore grates have been reduced (Broadhurst, 2000; Silva et al., 2011, 2012).

The use of a radial escape panel in conjunction with a funnel behind the TED (both versions of the Virgil Potter gear) also showed great promise. Perhaps most encouraging is that this gear was developed by a local fisherman (V. Potter) that participated in the workgroup process. Use of the Virgil Potter BRD with a 3.81-cm mesh codend resulted in lower bycatch reduction, relative to that from the use of the Virgil Potter BRD with a $4.45-\mathrm{cm}$ codend, but resulted in a gain in shrimp catch, on average, compared with the average loss in shrimp catch from use of the version with the codend that has the larger mesh size (Table 4).

Testing in 2017 focused on smaller vessels $(<14 \mathrm{~m})$ and the nearshore waters of North Carolina. Unlike the outcome of previous testing in 2015 and 2016 (Brown et al..$^{9}$ ), the results from testing in 2017 fell short of achieving the additional $40 \%$ reduction in finfish bycatch with the gear combinations used. Although the catch was not separated by species during trials, we did observe that striped anchovy (Anchoa hepsetus) made up the majority of the finfish catch for several tows conducted in ocean waters but were not observed in catch of tows conducted during the inshore testing in Pamlico Sound. Differences in species composition were likely a contributing factor in the underperformance of similar gears that had reached the $40 \%$ reduction goal during testing in inshore waters in previous years. Although the target for reduction of finfish bycatch was not achieved with the gears tested in our study in 2017 , the use of a TED with $7.62-\mathrm{cm}$ bar spacing in conjunction with 2 state fisheyes did show promise during testing in the summer on a small vessel. On the basis of results from testing in 2015 and 2016, it is anticipated that testing of a gear composed of a TED with 7.62-cm bar spacing, 2 state fisheyes, and a codend with a larger stretch mesh $(4.45-\mathrm{cm})$ would result in reductions in finfish bycatch greater than the $40 \%$ target. Further testing with this gear combination is needed in the smallboat fleet to accurately assess this expectation.

\section{Study design}

The use of a workgroup throughout this project played a critical role in achieving the finfish reduction goal set forth by the NCMFC. The fact that international trawl experts provided all participants with a basic understanding of trawl gear dynamics, fish behavior in trawls, results from recent research, and an overview of the scientific testing protocol to be used was instrumental in these achievements (Brown et al. ${ }^{9}$; NMFS ${ }^{11}$ ). Workgroup members from the fishing industry then provided ideas to be tested that they believed would work best within the parameters of Pamlico Sound, a shallow, muddy-bottom estuarine environment. Finally, facilitated discussion techniques were 
used to ensure consensus in the selection of gears to be tested. This process engaged industry participants and created ownership in the selections made, contributing to the project's success.

Some elements of the study design mandated by the NCMFC differed from typical collaborative research methods and BRD testing. For example, paired tow testing is best conducted during normal fishing conditions so that the true effects of experimental gear, relative to the standard gears used, can be determined (Eayrs, 2012). A condition of the award that sponsored the testing in 2015 required that industry partners contribute a $50 \%$ cost match. Requiring large industry matching funds can change the perceptions and expectations of the industry sector relative to those of scientific collaborators (Harte, 2001). Specifically, projects that deviate from a collaborative approach (e.g., requesting that fishermen fish out of season or, more importantly, fish by using experimental gear during normal conditions) operate outside of established parameters (Conway and Pomeroy, 2006). Collaborative research is difficult at best, and expectations of scientists and industry participants often do not align when only one of the partners-in this case, the shrimp industry-is asked to make concessions (Stephenson et al., 2016).

Our methods followed NOAA BRD testing protocols with a few exceptions. First, the establishment of a goal of $40 \%$ bycatch reduction over that achieved by the current industry trawl with TED and BRD installed was above and beyond normal testing design, requiring BRD combinations to be evaluated. Federal certification of a BRD prototype requires the use of the $\mathrm{BRD}$ to result in a consistent reduction of total finfish bycatch of at least $30 \%$, by weight, when compared with the use of a naked (TED, but no $\mathrm{BRD})$ control net $\left(\mathrm{NMFS}^{11}\right)$. Assuming, for instance, that by using our control net with a BRD we achieved a $30 \%$ reduction of finfish bycatch and by using our experimental net we achieved our goal of a $40 \%$ reduction of finfish bycatch by weight, we theoretically would have achieved the equivalent of $58 \%$ reduction over a naked net or nearly twice the federal requirement. Second, the protocol for regular switching of experimental gear to each side of the vessel was not always followed for a variety of reasons: lack of performance for a given gear, weather, or vessel captains not following agreed upon protocols. Finally, NOAA testing protocols require that testing achieve a minimum of 30 successful paired tows. The sponsor of our field season in 2015 requested that 60 successful paired tows be attempted but offered no scientific basis for deviation from the NOAA testing protocol of 30 paired tows $\left(\mathrm{NMFS}^{11}\right)$.

Although the level of decrease in shrimp catch is not part of the NOAA testing protocol, it was discussed during workgroup meetings. The results of previous collaborative testing with industry in the Gulf of Mexico indicate that a $10 \%$ loss in shrimp catch may be acceptable, as long as bycatch is greatly reduced by the gear (Crowley, 2014). During discussions in our study, members of the workgroup from the fishing industry indicated that a $3-5 \%$ decrease in shrimp catch would likely be acceptable but that acceptable loss would ultimately depend upon the level of bycatch reduction achieved. Because discussions on this topic happened largely before preliminary results were obtained, it will be worthwhile to reexamine the issue of shrimp loss in future collaborations now that significant finfish bycatch reductions have been observed.

\section{Gear evaluation}

The use of 2 statistical procedures to evaluate the paired tows resulted in similar outcomes in most cases. Unlike the paired $t$-test, the randomization test did not assume that the data were normally distributed. Another advantage of the randomization procedure was that it did not require tows to be dropped from the analysis. Finally, the $P$-values computed in the randomization procedure are exact and not asymptotic.

\section{Experimental gear costs}

Fabrication and installation costs of the 14 experimental gear configurations varied considerably. However, cost was not a good predictor of performance. The estimates of gear costs included in Table 1 were provided by a local net maker and workgroup member; lower costs may be expected if fishermen build and install their own shrimp trawls. Further, we do not have costs for building a new experimental gear (costs are only for modifying control gear). Shrimp trawl components, particularly codends, have a finite life span and must be replaced with heavy use. Additional cost savings are likely if new gear is to be built rather than existing gear is to be modified.

\section{Recommendations}

Although our initial findings are promising, continued testing is necessary for repeatability and to ensure consistent and reliable performance by gears under variable conditions prior to widespread voluntary adoption (Murray et al., 1992). Shrimp catch and bycatch results varied considerably by vessel and between 2015 and 2016, although fishing was conducted in the same general area during the relatively short shrimp season.

Further, we recommend continuing the industry workgroup and evaluation of experimental gears and gear combinations on both smaller class vessels $(<12 \mathrm{~m})$ and vessels that operate in the nearshore Atlantic Ocean $(<4.83 \mathrm{~km}$ from shore) in both the summer brown shrimp and autumn white shrimp fisheries. Smaller vessels accounted for approximately $66 \%$ of the fleet and for $64 \%$ of the effort by number of trips over the 5-year period 2013-2017 in North Carolina (Bianchi ${ }^{18}$ ). Although the majority of shrimp trawling effort in North Carolina typically occurs in estuarine waters, approximately $25 \%$ occurs in the nearshore Atlantic Ocean primarily $<4.83 \mathrm{~km}$ from shore (i.e., in state managed waters).

\footnotetext{
${ }^{18}$ Bianchi, A. 2017. Personal commun. Div. Mar. Fish., North Carolina Dep. Environ. Qual., 3441 Arendell St., Morehead City, NC 28557.
} 
Given additional time and funding, it would be worthwhile to explore bycatch reduction strategies beyond those tested here. The results of testing gear combinations in this study provide a strong basis by which to make adjustments. Despite the high levels of bycatch reduction achieved, $t$-test results indicate that the decrease of shrimp catch never exceeded $12.1 \%$ relative to that of the control net (Tables 3 and 4). In fact, loss of shrimp catch was significant only in 2 of $10 t$-tests, indicating that even more radical approaches could be considered. For example, would a $20 \%$ decrease in shrimp catch be acceptable if finfish bycatch could be reduced by $80 \%$ in the estuarine shrimp fishery? Given that significant shrimp loss (>15\%) would likely occur during the course of testing, future studies should consider funding that would compensate industry partners for lost revenue while adhering to strict testing protocols.

The importance of using a collaborative process for gear testing cannot be overstated. Projects that can combine the interests of both industry and resource management can often obtain multiple objectives and create successful cooperation between stakeholders (Yochum et al., 2011; Thornton and Scheer, 2012; O'Keefe and DeCelles., 2013). It would not have been possible to test 14 gears in the course of 3 sampling seasons without substantial and consistent industry input, involvement, and cost sharing of vessel time.

\section{Acknowledgments}

We thank the fishing vessel owners, captains, and crews and all workshop and workgroup members that participated in this collaborative effort. Special gratitude is extended in memory of the late S. Parrish, who served as a highly respected member of this workgroup and similar groups in the past. Funding was made available through the NCMFC's Conservation Fund, the North Carolina Sea Grant Program, the NOAA Bycatch Reduction Engineering Program (Award NA15NMF4720376), and the National Fish and Wildlife Foundation Fisheries Innovation Fund (Award 47988).

\section{Literature cited}

Andrew, N. L., and J. G. Pepperell. 1992. The by-catch of shrimp trawl fisheries. Oceanogr. Mar. Biol. Annu. Rev. 30:527-565.

Brewer, D., N. Rawlinson, S. Eayrs, and C. Burridge. 1998. An assessment of bycatch reduction devices in a tropical Australian prawn trawl fishery. Fish. Res. 36:195-215. Crossref

Broadhurst, M. K.

2000. Modifications to reduce bycatch in prawn trawls: a review and framework for development. Rev. Fish Biol. Fish. 10:27-60. Crossref

Conway, F. D. L., and C. Pomeroy.

2006. Evaluating the human-as well as the biologicalobjectives of cooperative fisheries research. Fisheries 31:447-454. Crossref
Crowder, L. B., and S. A. Murawski.

1998. Fisheries bycatch: implications for management. Fisheries 23(6):8-17. Crossref

Crowley, M.

2014. Towing trends: making strides in bycatch, bottom impacts, fuel savings. Natl. Fisherman 94(11):32-33, 37.

Davies, R. W. D., S. J. Cripps, A. Nickson, and G. Porter.

2009. Defining and estimating global marine fisheries bycatch. Mar. Policy 33:661-672. Crossref

Eayrs, S.

2012. Comparative testing of bycatch reduction devices in tropical shrimp-trawl fisheries: a practical guide, $122 \mathrm{p}$. FAO, Rome.

Engaas, A., D. Foster, B. D. Hataway, J. W. Watson, and I. Workman. 1999. The behavioral response of juvenile red snapper (Lutjanus campechanus) to shrimp trawls that utilize water flow modifications to induce escapement. Mar. Tech. Soc. J. 33(2):43-50. Crossref

Hall, M. A., D. L. Alverson, and K. I. Metuzals.

2000. By-catch: problems and solutions. Mar. Pollut. Bull. 41:204-219. Crossref

Harte, $\mathrm{M}$.

2001. Opportunities and barriers for industry-led fisheries research. Mar. Policy 25:159-167. Crossref

Hataway, D., D. Foster, and L. Saxon.

2017. Evaluations of turtle excluder devices (TEDs) with reduced bar spacing in the inshore penaeid shrimp fishery in the northern Gulf of Mexico. NOAA Tech. Memo. NMFS-SEFSC-707, $13 \mathrm{p}$.

Isaksen, B., J. W. Valdemarsen, R. B. Larsen, and L. Karlsen.

1992. Reduction of fish by-catch in shrimp trawl using a rigid separator grid in the aft belly. Fish. Res. 13:335-352. Crossref

Kelleher, K.

2005. Discards in the world's marine fisheries: an update. FAO Fish. Tech. Pap. 470, 131 p. FAO, Rome.

Manly, B. F. J.

2007. Randomization, bootstrap, and Monte Carlo methods in biology, 3rd ed., 480 p. Chapman and Hall/CRC, Boca Raton, FL.

Murray, J. D., J. J. Bahen, and R. A. Rulifson.

1992. Management considerations for by-catch in the North Carolina and southeast shrimp fishery. Fisheries 17(1):21-26. Crossref

NCDMF (North Carolina Division of Marine Fisheries).

2015. North Carolina shrimp fishery management plan, Amendment 1, 366 p. Div. Mar. Fish., North Carolina Dep. Environ. Nat. Resour., Morehead City, NC. [Available from website.]

Noell, C. J., M. K. Broadhurst, and S. J. Kennelly.

2018. Refining a Nordmøre-grid bycatch reduction device for Spencer Gulf penaeid-trawl fishery. PLoS ONE 13(11):e0207117. Crossref

O'Keefe, C. E., and G. R. DeCelles.

2013. Forming a partnership to avoid bycatch. Fisheries 38:434-444. Crossref

$\mathrm{R}$ Core Team.

2017. R: a language and environment for statistical computing. R Foundation for Statistical Computing, Vienna, Austria. [Available from website, accessed December 2017.]

Rulifson, R. A., J. D. Murray, and J. J. Bahen.

1992. Finfish catch reduction in the South Atlantic shrimp trawls using three designs of by-catch reduction devices. Fisheries 17(1):9-20. Crossref

SAFMC (South Atlantic Fishery Management Council).

1996. Final amendment 2 (bycatch reduction) to the fishery management plan for the shrimp fishery of the 
South Atlantic region, including a final supplemental environmental impact statement, regulatory impact review, and social impact assessment, 108 p. SAFMC, Charleston, SC. [Available from website.]

Scott-Denton, E., P. F. Cryer, M. R. Duffy, J. P. Gocke, M. R. Harrelson, D. L. Kinsella, J. M. Nance, J. R. Pulver, R. C. Smith, and J. A. Williams.

2012. Characterization of the U.S. Gulf of Mexico and South Atlantic penaeid and rock shrimp fisheries based on observer data. Mar. Fish. Rev. 74(4):1-27.

Silva, C. N. S., M. K. Broadhurst, A. Schwingel, J. H. Dias, A. P. Cattani, and H. L. Spach.

2011. Refining a Nordmøre-grid for a Brazilian artisanal penaeid-trawl fishery. Fish. Res. 109:168-178. Crossref

Silva, C. N. S., M. K. Broadhurst, J. H. Dias, A. P. Cattani, and

H. L. Spach.

2012. The effects of Nordmøre-grid bar spacings on catches in a Brazilian artisanal shrimp fishery. Fish. Res. 127128:188-193. Crossref

Stephenson, R. L., S. Paul, M. A. Pastoors, M. Kraan, P. Holm,

M. Wiber, S. Mackinson, D. J. Dankel, K. Brooks, and A. Benson. 2016. Integrating fishers' knowledge research in science and management. ICES J. Mar. Sci. 73:1459-1465. Crossref

Thornton, T. F., and A. M. Scheer.

2012. Collaborative engagement of local and traditional knowledge and science in marine environments: a review. Ecol. Soc. 17(3):8. Crossref
Vieira, W. J., M. M. Domingos, J. L. Rodrigues-Filho, and E. G. Gentil de Farias.

2017. Kite escape device: a new approach to reduce bycatch in shrimp trawls. Mar. Coast. Fish. 9:396-403. Crossref

Wardle, C. S.

1986. Fish behaviour and fishing gear. In The behaviour of teleost fishes (T. J. Pitcher, ed.), p. 463-495. Springer, Boston, MA.

Watson, J. W., Jr., and C. McVea Jr.

1977. Development of a selective shrimp trawl for southeastern United States penaeid shrimp fisheries. Mar. Fish. Rev. 39(10):18-23.

Watson, J., D. Foster, S. Nichols, A. Shah, E. Scoll-oenlon, and J. Nance.

1999. The development of bycatch reduction technology in the southeastern United States shrimp fishery. Mar. Technol. Soc. J. 33(2):51-56. Crossref

Winger, P. D., S. Eayrs, and C. W. Glass.

2010. Fish behavior near bottom trawls. In Behavior of marine fishes: capture processes and conservation challenges (Pingguo He, ed.), p. 65-103. Blackwell Publishing, Ames, IA.

Yochum, N., R. M. Starr, and D. E. Wendt.

2011. Utilizing fishermen knowledge and expertise: keys to success for collaborative fisheries research. Fisheries 36:593-605. Crossref 